\title{
Ecological Security Evaluation and Spatial-temporal Evolution Characteristics of Natural Resources Based on Wind-Driven Optimization Algorithm_-A case study of Guangdong-Hong Kong-Macao Greater Bay Area
}

\author{
Xiaoling $\mathrm{Ke}^{1}$, wei shi ${ }^{1}$, Chang Yang ${ }^{1}$, Haixiang Guo ${ }^{1}$, and Amal Mougharbel ${ }^{2}$ \\ ${ }^{1}$ China University of Geosciences \\ ${ }^{2}$ International Technological University
}

October 5, 2021

\begin{abstract}
As a complex system, the urban natural resources system comprises water, land, forest, and air resources. Natural resources are the essential elements of economic and social development and the source of sustainable urban development. However, there are few articles which regard different natural resources as a comprehensive system to evaluate. This study aimed to reveal the patterns of natural resources and highlight the impact of natural resource subsystem. Firstly, this study establishes the ecological security evaluation system of natural resources based on the "Driving Force-Pressure-State-Response" model. Secondly, we use the Wind-Driven Optimization algorithm to optimize the Projection Pursuit model to calculate the value of ecological security level and the comprehensive value of ecological security in Guangdong-Hong Kong-Macao Greater Bay Area (2013-2018). The temporal characteristics and spatial layout of natural resources ecological security, the impact of mechanism of water, land, forest, and air resources subsystems on natural resources ecological security were assessed. The results shows that the ecological security level of natural resources in nine cities of Guangdong-Hong Kong-Macao Greater Bay Area is on the rise as a whole from 2013 to 2018. However, the ecological security level in the central region of the Greater Bay Area is low, which is directly related to the severe environmental pollution of its water and air resources. The results are basically consistent with the actual situation, which can provide a reference for the ecological security evaluation of natural resources in other urban agglomerations.
\end{abstract}

Ecological Security Evaluation and Spatial-temporal Evolution Characteristics of Natural Resources Based on Wind-Driven Optimization Algorithm

\section{A case study of Guangdong-Hong Kong-Macao Greater Bay Area}

Journal name: Land Degradation \& Development

Short running title: Ecological Security Evaluation of Natural Resources

Xiaoling $\mathrm{Ke}^{1,2}$, Wei Shi ${ }^{1}$, Chang Yang ${ }^{1}$, Haixiang Guo ${ }^{1}$, Amal Mougharbel ${ }^{3}$

${ }^{1}$ School of Economics and Management, China University of Geosciences, Wuhan, P.R. China;

${ }^{2}$ Center for Energy Environmental Management and Decision-making, China University of Geosciences(Wuhan), Wuhan, P.R. China;

${ }^{3}$ Business Administration Department, International Technological University, CA, USA;

Email address of all authors: 
Xiaoling Ke (Corresponding author):kxlcug@163.com

Wei Shi: Shiwei960618@163.com

Chang Yang: 18713272839@163.com

Haixiang Guo:faterdumk0732@sina.com

Amal Mougharbel:amougharbel@itu.edu

\begin{abstract}
As a complex system, the urban natural resources system comprises water, land, forest, and air resources. Natural resources are the essential elements of economic and social development and the source of sustainable urban development. However, there are few articles which regard different natural resources as a comprehensive system to evaluate. This study aimed to reveal the patterns of natural resources and highlight the impact of natural resource subsystem. Firstly, this study establishes the ecological security evaluation system of natural resources based on the "Driving Force-Pressure-State-Response" model. Secondly, we use the Wind-Driven Optimization algorithm to optimize the Projection Pursuit model to calculate the value of ecological security level and the comprehensive value of ecological security in Guangdong-Hong KongMacao Greater Bay Area (2013-2018). The temporal characteristics and spatial layout of natural resources ecological security, the impact of mechanism of water, land, forest, and air resources subsystems on natural resources ecological security were assessed. The results shows that the ecological security level of natural resources in nine cities of Guangdong-Hong Kong-Macao Greater Bay Area is on the rise as a whole from 2013 to 2018. However, the ecological security level in the central region of the Greater Bay Area is low, which is directly related to the severe environmental pollution of its water and air resources. The results are basically consistent with the actual situation, which can provide a reference for the ecological security evaluation of natural resources in other urban agglomerations.
\end{abstract}

\title{
Keywords
}

Ecological security of natural resources, Guangdong-Hong Kong-Macao Greater Bay Area, Projection Pursuit model, Wind-Driven Optimization algorithm, Spatial layout

\section{Statements}

Data availability statement: The authors promise that the data, materials support their results and conclusion. The authors have permissions for use of MATLAB 2018, and its code support results in this article.

Funding statement: This article was funded by the National Science Foundation of China (Grant No. 72074198) and the Hubei Social Science Project (Grant No. 2020049).

Conflicts of interest disclosure: It is responsibility of the corresponding author to review this policy with all authors and collectively to disclose with the submission all pertinent commercial and other relationships. And the authors declare that they have no financial interests.

Ethical approval statement: This article is original and honest, and it does not contain any studies with human participants or animals performed by any of the authors.

Permission to reproduce material from other sources: All authors do not permit reproduce the materials in this article from other sources.

\section{Authorship}

All authors contributed to the study conception and design. Material preparation, data collection and analysis were performed by Xiaoling Ke and Wei Shi. Writing was performed by Xiaoling Ke, Wei Shi, Chang Yang and Amal Mougharbel. Funding was acquired from the program of Xiaoling Ke and Haixiang 
Guo. The first draft of the manuscript was written by Xiaoling Ke and all authors commend on previous versions of the manuscript. All authors read and approved the final manuscript.

Authors' addresses: Xiaoling Ke, Wei Shi, Chang Yang, and Haixiang Guo whose address is "School of Economics and Management, China University of Geosciences, Wuhan, P.R. China, 430074". Amal Mougharbel whose address is "Business Administration Department, International Technological University, CA, 95113, USA".

\section{Acknowledgements}

The authors would like to acknowledge the National Natural Science Foundation of China (Grant No.72074198) and the Hubei Social Science Project (Grant No. 2020049) for the financial support.

\section{Hosted file}

main text .docx available at https://authorea.com/users/439521/articles/540416-ecologicalsecurity-evaluation-and-spatial-temporal-evolution-characteristics-of-natural-resourcesbased-on-wind-driven-optimization-algorithm-a-case-study-of-guangdong-hong-kong-macaogreater-bay-area

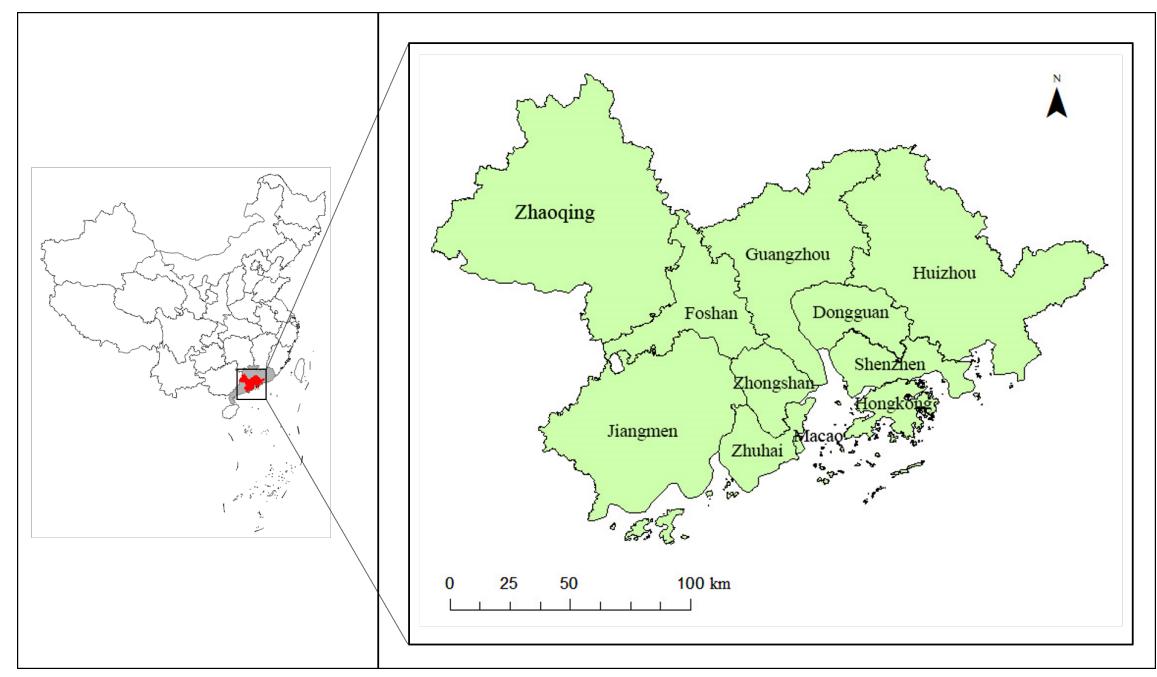




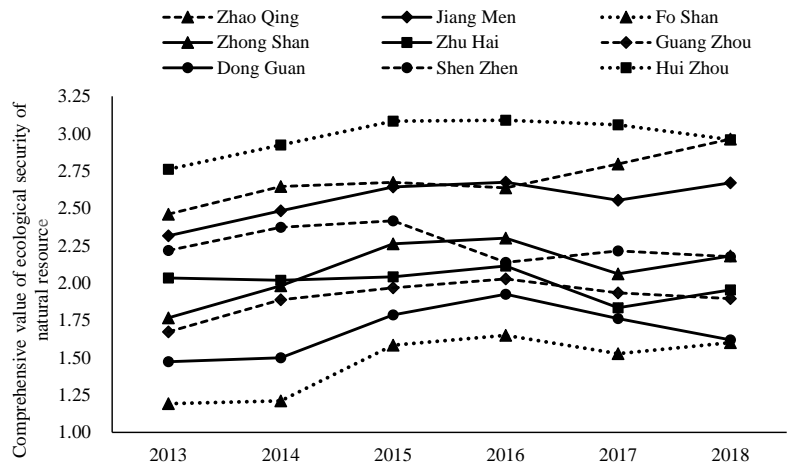

FIGURE 2 Comprehensive value of ecological security of natural resources in Guangdong-Hong Kong-Macao Greater Bay Area from 2013 to 2018 

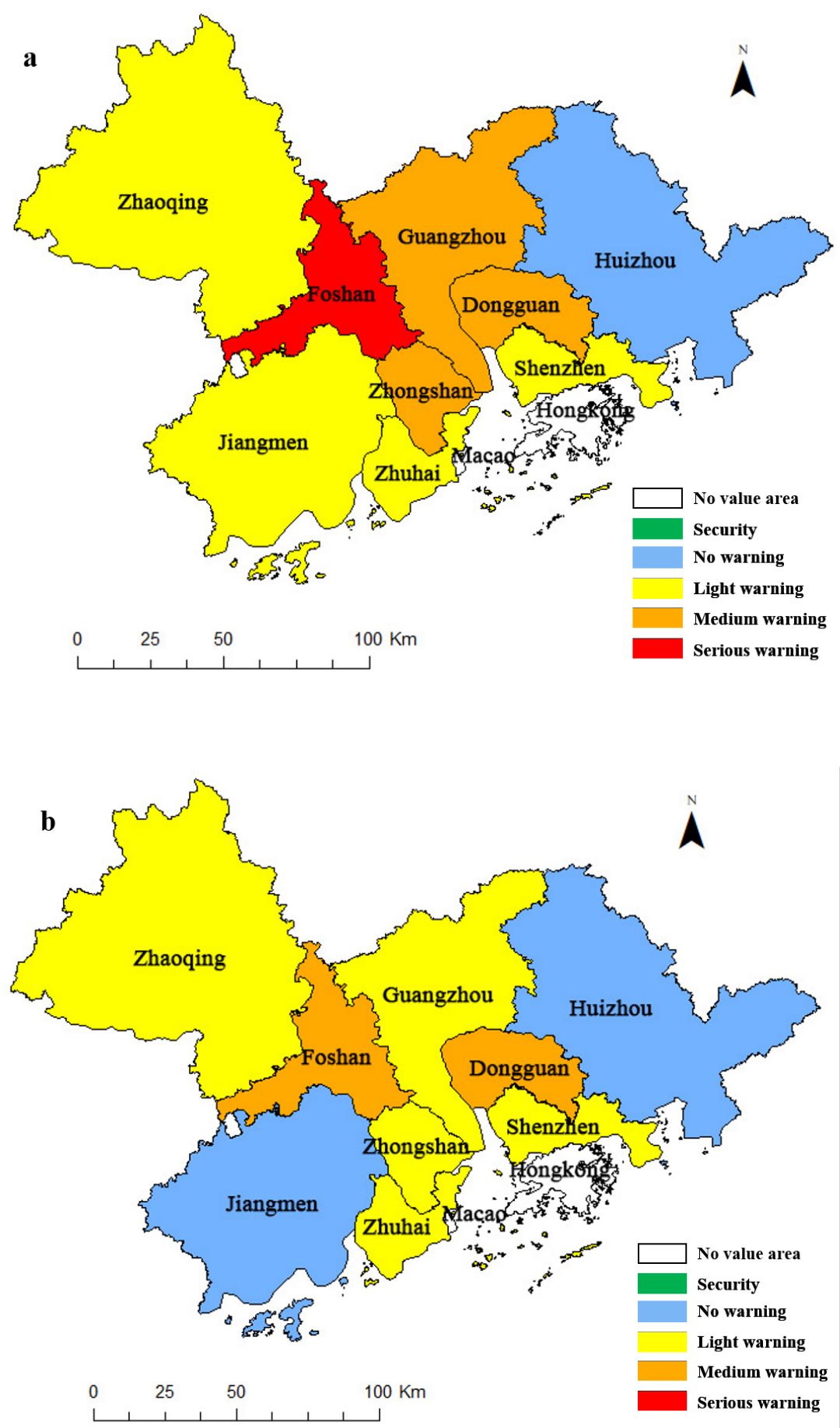

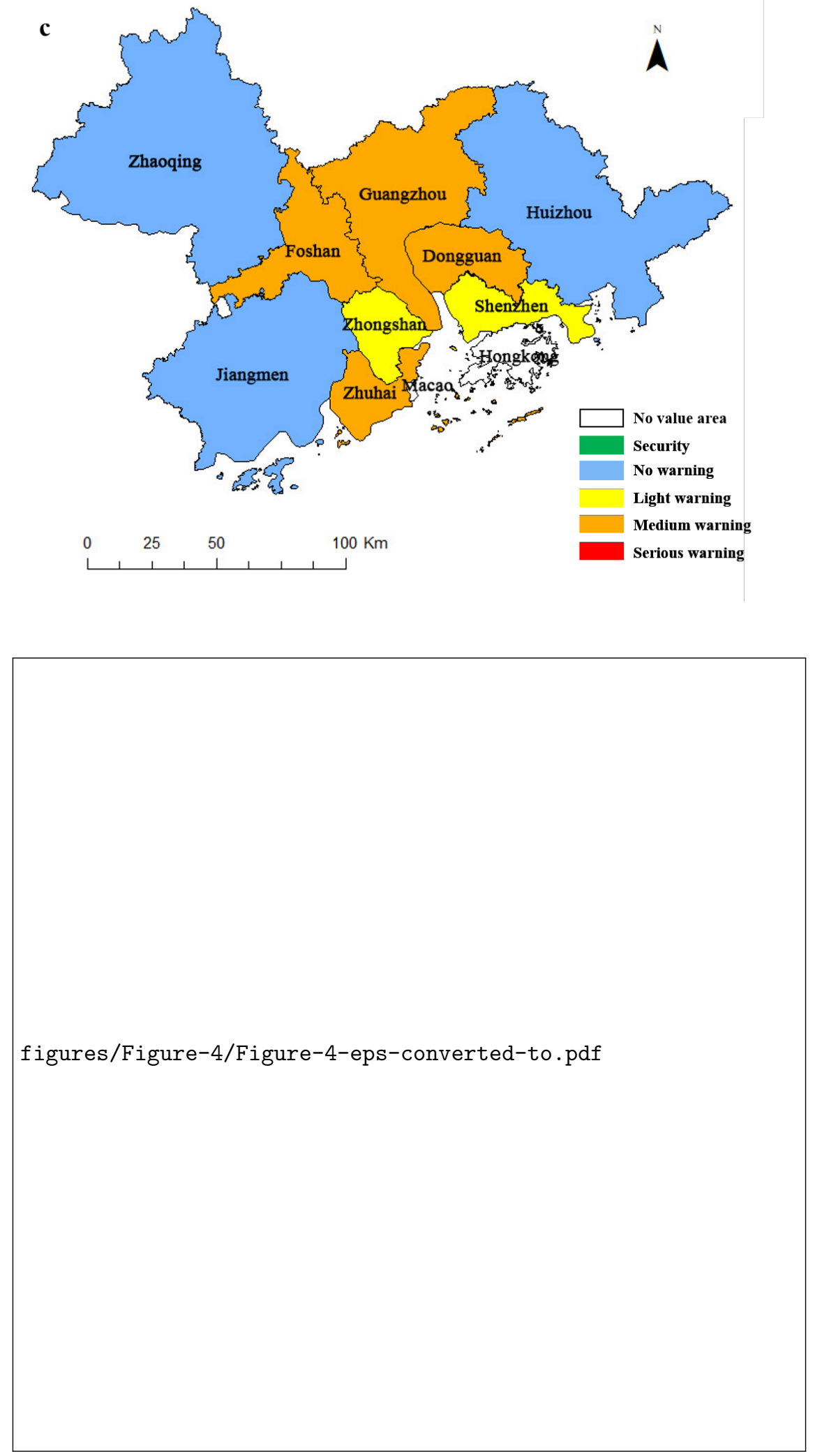